\title{
Haemodynamic Effects of Salbutamol in Patients needing Circulatory Support after Open-heart Surgery
}

\author{
S. D. WYSE, D. G. GIBSON, M. A. BRANTHWAITE
}

British Medical fournal, 1974, 3, 502-503

\section{Summary}

The effects of substituting an infusion of salbutamol for isoprenaline were studied in 12 patients needing circulatory support after valve replacement surgery. The cardiac output rose while the heart rate remained unaltered. There was a reduction in systemic vascular resistance, and though the oxygen uptake tended to rise the increase in cardiac output was proportionately greater so that the arteriovenous oxygen difference fell.

It is suggested that the drug is of value for two reasons. It causes a selective reduction in peripheral arteriolar resistance, which avoids peripheral pooling, but permits limited myocardial work to be used to generate flow rather than pressure, and the increase in cardiac output is not accompanied by a corresponding rise in oxygen uptake.

\section{Introduction}

The drug treatment of patients with a low cardiac output due to severe heart disease is a difficult therapeutic problem. Though isoprenaline remains a standard drug in this situation it has disadvantages, including a tendency to cause arrhythmias or inappropriate tachycardia, particularly in patients with atrial fibrillation, and to increase myocardial and total body oxygen requirements secondary to its metabolic effects. A previous investigation (Gibson and Coltart, 1971) indicated that these effects would be less marked when a comparable increase in cardiac output was brought about by salbutamol infusion, and the authors suggested that the drug might be of value in the treatment of low output states due to cardiogenic shock. Acting on this Lal et al. (1972) claimed clinical evidence of improvement in nine out of 12 patients suffering from cardiogenic shock after myocardial infarction who were treated with intravenous injections of salbutamol (1-2 mg). The present study was designed to investigate the effect of substituting salbutamol for isoprenaline in a group of patients whose clinical condition needed circulatory support after open-heart surgery.

\section{Patients and Methods}

Twelve patients (average age 48 years) were studied in the first eight hours after valve replacement surgery. All needed intermittent positive pressure ventilation and had been established on an isoprenaline infusion during the closing stages of surgery by staff who did not take part in the postoperative study. The indication for instituting this infusion was hypotension, with or without oliguria and evidence of peripheral vasoconstriction, and the infusion rate $(0.5-1.6 \mu \mathrm{g} / \mathrm{min})$ had been selected according to the response of blood pressure and heart rate to incremental bolus doses. On admission to the intensive therapy unit the arterial blood pressure was well maintained (mean

Brompton Hospital, Fulham Road, London SW3 6HP S. D. WYSE, P.F.A., R.C.S., Research Assistant, Anaesthetic Department

M. A. BRANTHWAITE, M.R.C.P., F.F.A. R.C.S., Consultant Anaesthetist
( \pm S.D.) $98 \pm 10 \mathrm{~mm} \mathrm{Hg}$ ), but all patients were vasoconstricted and sweating and several were still oliguric (urine output less than $0.5 \mathrm{ml} / \mathrm{kg} / \mathrm{hr}$ ).

Radial arterial, internal jugular, left atrial, and pulmonary arterial catheters are inserted routinely in this unit in patients who are considered likely to need detailed cardiovascular assessment in the postoperative period. In the present study, pressures were recorded through these catheters using Bell and Howell transducers, an amplifier unit (St. Thomas's Hospital electronics department), and a photographic recorder (New Electronic Products Ltd.). Mean pressures were derived electronically and zero was referred to the midaxillary line. Cardiac output was measured by the thermal dilution technique using a Devices monitor and thermal sensing catheter. The latter was introduced into the pulmonary artery through the catheter, which was already in situ. Each value for the cardiac output was derived from the mean of at least three determinations; the performance of the monitor under these conditions had been validated previously against the Fick technique $(r=0.8$; S.E. $0.31 . / \mathrm{min}$. )

Blood samples were collected from radial and pulmonary arterial catheters into heparinized syringes and were stored in ice until analyzed for oxygen content using a Lex- $\mathrm{O}_{2}-\mathrm{Con}$ (Lexington Instruments Ltd.). Standard equations were used to determine stroke volume, vascular resistances, stroke work, and oxygen uptake per minute.

Drugs were administered through a separate venous catheter which was not used for pressure measurements or blood transfusion so that infusion rates could be kept constant. Isoprenaline sulphate $(5 \mathrm{mg})$ or salbutamol $(25 \mathrm{mg})$ were dissolved in $500 \mathrm{ml} 5 \%$ dextrose solution and delivered using an IVAC infusion pump. Initial observations were made in all patients within one hour of returning from the operating theatre and while the infusion of isoprenaline remained unaltered. In seven patients salbutamol (8-27 $\mu \mathrm{g} / \mathrm{min})$ was substituted immediately after these preliminary observations had been completed and in three more patients after observations during isoprenaline infusion had been continued for four hours. The infusion rate was selected according to the existing isoprenaline regimen, salbutamol being used at about 15 times the dose of isoprenaline. Serial measurements were made at 15-minute intervals for one and a half hours and then every 30 minutes for a further two and a half hours. Two patients were treated with isoprenaline throughout and studied for a similar period. The results in these two patients together with those obtained from the three patients studied for four hours before salbutamol was substituted for isoprenaline were used as a basis for comparison between the effects of the two drugs.

There were no side effects as a result of these treatments and 11 of the 12 patients survived.

\section{Results}

The results are given in detail in the table. In all cases the cardiac index was low initially and the arteriovenous oxygen difference was high. After substitution of salbutamol there was a significant increase in cardiac output which was achieved by an increase in stroke volume with no change in heart rate. Oxygen uptake tended to rise but the increase in cardiac output was proportionately greater so that the arteriovenous oxygen difference fell. There was a considerable reduction in systemic vascular resistance, but pulmonary vascular resistance was 
Findings after Substituting Salbutamol for Isoprenaline in Patients needing Circulatory Support

\begin{tabular}{|c|c|c|c|c|}
\hline & $\begin{array}{l}\text { During Isoprenaline } \\
\text { Infusion } \\
\text { (Mean } \pm \text { S.D.) }\end{array}$ & $\begin{array}{l}\text { 45 Minutes after } \\
\text { Substitution of } \\
\text { Salbutamol } \\
\text { (Mean Difference } \\
\pm \text { S.E. of Mean) }\end{array}$ & $\begin{array}{l}\text { Four Hours after } \\
\text { Substitution of } \\
\text { Salbutamol } \\
\text { (Mean Difference } \\
\pm \text { S.E. of Mean) }\end{array}$ & $\begin{array}{c}\text { Significance of } \\
\text { Change at } 4 \text { Hours } \\
\mathbf{P}\end{array}$ \\
\hline $\begin{array}{l}\text { Cardiac index }\left(1 . / \mathrm{min} / \mathrm{m}^{2}\right) \\
\text { Heart rate }(\text { beat } / \mathrm{min}) \\
\text { Stroke volume }(\mathrm{ml}) \\
\text { Mean arterial pressure (mm Hg) } \\
\text { Mean pulmonary arterial pressure }(\mathrm{mm} \mathrm{Hg}) \\
\text { Mean left atrial pressure }(\mathrm{mm} \mathrm{Hg}) \\
\text { Mean right atrial pressure }(\mathrm{mm} \mathrm{Hg}) \\
\text { Systemic vascular resistance }(\mu) \\
\text { Pulmonary vascular resistance }(\mu) \\
\text { Vol. \% Arteriovenous oxygen difference } \\
\text { Oxygen consumption (ml/min) } \\
\text { Left ventricular stroke work }(\mathrm{g}-\mathrm{m}) * \\
\text { Right ventricular stroke work }(\mathrm{g}-\mathrm{m})^{*}\end{array}$ & 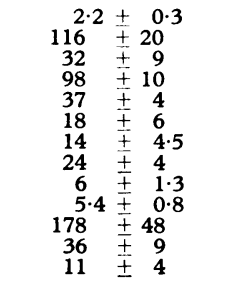 & 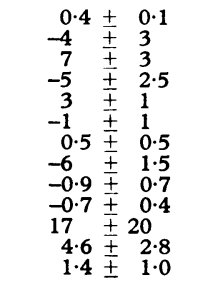 & 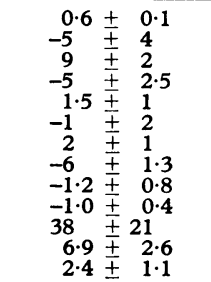 & $\begin{array}{l}<0 \cdot 001 \\
\text { N.S. } \\
<0 \cdot 01 \\
\text { N.S. } \\
\text { N.S. } \\
\text { N.S. } \\
\text { N.S. } \\
<0 \cdot 01 \\
\text { N.S. } \\
<0 \cdot 05 \\
\text { N.S. } \\
\text { N.S. } \\
\text { N.S. }\end{array}$ \\
\hline
\end{tabular}

*Gram metre

N.S. = Not significant.

unchanged. These haemodynamic changes occurred abruptly 30 to 45 minutes after the change to salbutamol with little further alteration thereafter. In the three patients who remained on isoprenaline for four hours changes were slight and statistically insignificant. In two out of these three subsequent transition from isoprenaline to salbutamol resulted in increases in cardiac output of 0.5 and $1.01 . / \mathrm{min}$ respectively, while in the third neither salbutamol nor an increased rate of isoprenaline infusion produced any measureable improvement.

\section{Discussion}

Haemodynamic conditions are unstable in the immediate postoperative period and the welfare of the patient often precludes a rigorous trial procedure. All our patients needed catecholamine infusion on account of hypotension, peripheral vasoconstriction, or oliguria, and it was considered inadvisable to stop treatment for control observations. Instead the investigation was designed to observe the effects of substituting salbutamol for isoprenaline infusion and to compare the clinical course of these patients with that of a group in whom therapy with isoprenaline remained unaltered. The alternative, to study less severely ill patients, was rejected since it is not possible to extrapolate the results of such an investigation to those with more severe impairment of cardiac function in whom the drugs are actually needed on clinical grounds.

Substitution of salbutamol for isoprenaline led to a $25 \%$ increase in cardiac output and a reduction in systemic vascular resistance with no significant change in heart rate or oxygen uptake. Though no formal attempt was made to assess myocardial contractility the absence of change in ventricular stroke work at constant atrial pressure suggested that the increases in cardiac output and stroke volume were not mediated by a positive inotropic effect (Sarnoff and Berglund, 1954). The results imply that the increase in cardiac output was due instead to an action on the peripheral circulation, and they are in keeping with those of a previous study in a different population of patients (Gibson and Coltart, 1971). It has been shown that salbutamol is two to five times less potent than isoprenaline in dilating the peripheral vasculature in dogs and has only 1000th of the potency of isoprenaline as a cardiac stimulant (Cullum et al., 1969; Daly et al., 1971), and it was therefore possible to use a relatively large dose of salbutamol and consequently to achieve greater peripheral vasodilatation without alteration in heart rate or rhythm.

The reduction in systemic vascular resistance allowed limited myocardial work to be used to generate flow rather than pressure, while the constancy of right and left atrial pressures and the lack of obvious change in transfusion requirements suggest that peripheral pooling did not occur. The ability of salbutamol to act selectively on arteriolar resistance while leaving other components of the sympathetic nervous system intact is clearly valuable in a drug which is to be used in the treatment of patients with severe heart disease.

A second advantage of salbutamol is that the increase in cardiac output was not associated with a corresponding increase in oxygen uptake and in this respect it differs from agents with a more marked positive inotropic effect such as isoprenaline. In severe heart disease there is often a disproportionate reduction in cardiac output relative to total body oxygen requirements. A drug which increases oxygen uptake as well as cardiac output does not therefore necessarily improve the situation and may even aggravate it, either when cardiac function is so impaired that no increase in output is possible by pharmacological means, or if myocardial oxygen consumption is increased without a comparable change in coronary blood flow (Gunnar et al., 1967). The preferential increase in cardiac output caused by salbutamol was clearly shown in the present study by the significant narrowing of the arteriovenous oxygen difference. These advantages were often apparent clinically, and we now use the drug routinely in the postoperative care of patients needing circulatory support after open-heart surgery.

S.D.W. was supported by a grant from the Board of Governors, National Heart and Chest Hospitals.

We thank Allen and Hanbury for supplies of salbutamol.

\section{References}

Cullum, V. A., et al. (1969). British fournal of Pharmacology, 35, 141. Daly, M. J., Farmer, J. B., and Levy, G. P. (1971). British fournal of Pharmacology, 43, 624

Gibson, D. G., and Coltart, D. J. (1971). Postgraduate Medical fournal, 47, Suppl. (March), p. 40.

Gunnar, R. M., et al., (1967). Fournal of the American Medical Association 202,1124 .

Lal, S., et al. (1972). Lancet, 1, 853.

Sarnoff, S. J., and Berglund, E. (1954). Circulation, 9, 706. 